\title{
A PIRLS approach to literary understanding in secondary education
}

\author{
Peter Broeder ${ }^{1}$ and Carel van Wijk ${ }^{2}$ \\ ${ }^{1}$ Tilburg University, Babylon and Department of Culture Studies, 5000 LE Tilburg, The Netherlands \\ 2 Tilburg University, Department of Communication and Information Sciences, \\ 5000 LE Tilburg, The Netherlands
}

\begin{abstract}
This study explores the reading behaviour of secondary school students at about 16 years of age. Their actual performance was assessed with a specially compiled comprehension test covering four levels of text understanding. The test consisted of a set multiple choice items about a one-page passage from a literary novel. This procedure was derived from the PIRLS testing methodology for students of about 12 years old. We managed to successfully apply it to the older age group. The scores displayed the assumed decline in comprehension with increasing item difficulty. The performances showed diverging relations with personal characteristics. There were no differences in regard to ethnicity or gender. There were large differences in the scores between the educational levels investigated, students from vocational education showing considerably lower cores than grammar school students.
\end{abstract}

\section{Introduction}

\subsection{Literary skills in education}

Teachers often claim that students' proficiency in understanding texts is not sufficient for the successful completion of their courses. Students' comparatively low reading competence is responsible for all kinds of literacy problems in the classroom, and it ultimately affects school success [1].

To substantiate these claims of alleged shortcomings, we surveyed young adults' literary competences (ages 15-16). We assessed their actual performances on a specially compiled comprehension test with respect to four levels of understanding, from recognition of literal elements to inferences of causal relations and integration with world knowledge. These objective measurements were compared with participants' subjective self-assessments.

We applied the framework provided by the PIRLS-project [2]. This is a large international survey of literacy held among elementary school students (aged 9-10). We adapted the PIRLS methodology for use with secondary school children (aged 15-16). In addition, we wanted to find out whether secondary school pupils displayed systematic differences in reading skills in relation to educational level, gender and ethnicity.

This is an Open Access article distributed under the terms of the Creative Commons Attribution License 4.0, which permits unrestricted use, distribution, and reproduction in any medium, provided the original work is properly cited. 


\subsection{Objectives of the PIRLS project}

The PIRLS project (Progress in Reading Literacy Study) focuses on the reading level (achievement) and reading experiences of children in $4^{\text {th }}$ grade (aged 9-10). Every 5 years since 2001, information has been collected on reading behavior, reading attitude and reading proficiency. This is done for a large number of countries, cultures, and languages (52 countries in 2011). PIRLS is designed to help countries improve the teaching and learning of reading. The goal is to provide policy makers and teachers with the information they need to help all students become better readers [2]. And indeed, the impact of the international bench-marking of the educational systems in the countries involved has been substantial and has raised a lot of public attention, especially with respect to the effectiveness of local educational systems. A simple Google search for "PIRLS 2011" yields the following quotes, which are quite illustrative for the impact of the project:

"States [in the US] with the biggest gaps are ..",

"Dutch children perform well (rank 10), but hardly excel",

"Best education system Singapore",

"Including exam training in curriculum results in higher PIRLS scores".

The PIRLS framework distinguishes two purposes for reading, often associated with a text type:

- Reading for literary experience (reading narrative fiction),

- Reading to acquire and use information (reading informative articles and instructional texts).

In constructing meaning, the reader focuses on specific ideas, makes inferences, interprets and integrates information and ideas, and examines and evaluates text content. The PIRLS assessment of reading distinguishes four levels of understanding:

Level 1 (Low): Recognizing information stated explicitly in the text.

Level 2 (Intermediate): Inferring information that follows directly from the text.

Level 3 (High): Interpreting and integrating information found in different parts of the text.

Level 4 (Advanced): $\quad$ Evaluating textual information in relation with extra-textual sources (world knowledge).

\subsection{Research questions}

Three questions are central to our study. The first two concern our adaptation of the PIRLS approach $[2,3]$. The third is related to the empirical embedding of the instrument $[4,5]$. The first question is whether it is possible to test literary understanding using a short passage from a (larger) novel. The second is whether it is possible for each of the four levels of understanding to cast all items in a multiple choice format. The subsequent and third question is whether secondary school pupils display systematic differences on the test in relation to their educational level, gender and ethnicity.

\section{Method}

\subsection{Sample characteristics}

In the spring of 2012, a survey was carried out in which a total of 949 secondary school pupils participated. They all lived in the southern part of the Netherlands and were aged 15 to 18 (mean 16.1 years of age). Participants were recruited in such a way that they were evenly spread over school type (vocational training, grammar school), gender (boy, girl) and ethnicity (native Dutch, immigrant non-Dutch). 


\subsection{Questionnaire}

A passage was selected from a novel by A.F.Th. van der Heijden [6], currently one of the foremost literary authors in the Netherlands. It is a one-page passage in which an eye-witness account is given of events taking place in Amsterdam on April 30, 1980 during the coronation of Queen Beatrix. That day there were heavy protests against the shortage of affordable housing, instigated by squatters and resulting in fierce fights with the police. The main character in the novel reports his experiences on passing the Blauwbrug (Blue Bridge). We chose this particular passage because it combines the two text types central within the PIRLS framework, i.e., narrative fiction and informative/instructional text. The questionnaire consisted of four sets of items: one set with the actual test items, one set with text evaluations as a control measure, and two sets with self-assessment questions to provide background information on the test results. These sets are specified in (1) to (4).

(1) Testing text understanding

For each level of understanding, four (multiple choice) items were formulated, drawn up in accordance with the instructions given in the PIRLS 2011 Item Writing Guidelines [3]. Examples are:

Level 1: Recognizing information stated explicitly in the text

E.g. What color were the uniforms of the police?

Black - blue - green - gray.

Level 2: Inferring information that follows directly from the text

E.g. What made the police look like robots?

Their masks - their shields - their uniforms - their marching

Level 3: Interpreting and integrating information found in different parts of the text

E.g. What showed that the police felt threatened?

They withdrew back to back - they took a straddle-legged positionthey put on gas masks - they speeded up their assaults.

Level 4: Evaluating information in relation with extra-textual sources (world knowledge)

E.g. What did the main character think of the fighting parties?

The police were fairly rough - the protesters were going to losethe police were going to lose - the protesters were fairly rough.

(2) Evaluations of story and protagonist

Students evaluated the text from two perspectives - the story and its protagonist - on 7-points disagreelagree-scales. With regard to the story, the questions focused on three aspects: readability (6 items: I think this story is difficult to read, hard to follow, difficult to understand, clear, wellstructured, transparent), appropriateness (3 items: I think this story is strange, weird, odd), and attractiveness ( 3 items:I think this story is exciting, thrilling, compelling). For the protagonist, the questions concentrated on the degree of empathy (2 items: I sympathize with the feelings of the main character, I like the main character). For each aspects homogeneity of the scale was sufficient (Cronbach's alpha .70 or higher).

(3) Self-assessment of performance on the test

Students were asked to estimate the percentage of items they thought they had answered correctly, and to indicate on a 7-points disagree/agree-scale how easy they found the test to complete. 
Table 1. Self-assessment of reading proficiency in relation to Gender, Ethnicity and School Type (minimum 1, maximum 10).

\begin{tabular}{|c|c|c|c|c|c|c|}
\hline & \multicolumn{2}{|c|}{ Gender } & \multicolumn{2}{|c|}{ Ethnicity } & \multicolumn{2}{|c|}{ School Type } \\
\hline & $\begin{array}{l}\text { Boy } \\
(n=467)\end{array}$ & $\begin{array}{l}\text { Girl } \\
(n=477)\end{array}$ & $\begin{array}{l}\text { Dutch } \\
(n=470)\end{array}$ & $\begin{array}{l}\text { non-Dutch } \\
(\mathrm{n}=474)\end{array}$ & $\begin{array}{l}\text { Vocational } \\
(n=473)\end{array}$ & $\begin{array}{l}\text { Grammar } \\
(n=471)\end{array}$ \\
\hline Grade & 6.26 & 6.83 & 6.53 & 6.57 & 6.33 & 6.77 \\
\hline
\end{tabular}

Note: If a difference is significant, the background of the highest score is shaded.

4) Self-assessment of reading proficiency in general

Students scored their reading proficiency on the traditional 10-points scale used in the Dutch educational system (1 being extremely poor; 10 being excellent) (For reading proficiency I would grade myself $\left.a_{-}\right)$.

\section{Results}

All dependent measures were evaluated statistically with a three-way MANOVA. Independent factors were Gender (boy, girl), Ethnicity (native Dutch, immigrant non-Dutch), and School Type (vocational training, grammar school). Given the large sample size, a result is considered non-trivial if the statistical significance is less than $.01(\mathrm{p}<.01)$, and the effect size at least medium $\left(\eta_{p}^{2}>.059\right)$.

\subsection{Self-assessment of reading proficiency}

Table 1 gives an overview of the self-assessments of reading proficiency in relation to gender, ethnicity, and school type. Results can be summarized as follows:

- Girls scored their own reading proficiency significantly higher than boys did.

- Dutch and non-Dutch students hardly differed in their self-assessment.

- Grammar school students scored their reading proficiency significantly higher than did vocational school students.

\subsection{Evaluations of story and protagonist}

Table 2 gives an overview of the text evaluations in relation to gender, ethnicity, and school type. Results can be summarized as follows:

- Boys scored each evaluation aspect significantly higher than girls did.

- Dutch and non-Dutch students hardly differed in their evaluations.

- Grammar schools students scored each evaluation aspect significantly higher than did vocational school students.

\subsection{Self-assessment of performance on the test}

Table 3 gives an overview of the self-assessments on test performance in relation to gender, ethnicity, and school type. Results can be summarized as follows:

- Boys showed significantly higher scores than girls did on both correctness and easiness.

- Dutch and non-Dutch students showed no differences at all.

- Grammar schools students showed significantly higher scores than vocational school students on both measures. 
Table 2. Text evaluations in relation to Gender, Ethnicity and School Type (minimum 1, maximum 7).

\begin{tabular}{|c|c|c|c|c|c|c|}
\hline & \multicolumn{2}{|c|}{ Gender } & \multicolumn{2}{|c|}{ Ethnicity } & \multicolumn{2}{|c|}{ School Type } \\
\hline & $\begin{array}{l}\text { Boy } \\
(n=472)\end{array}$ & $\begin{array}{l}\text { Girl } \\
(n=478)\end{array}$ & $\begin{array}{l}\text { Dutch } \\
(n=474)\end{array}$ & $\begin{array}{l}\text { non-Dutch } \\
(\mathrm{n}=476)\end{array}$ & $\begin{array}{l}\text { Vocational } \\
(n=478)\end{array}$ & $\begin{array}{l}\text { Grammar } \\
(\mathrm{n}=472)\end{array}$ \\
\hline Readability & 4.10 & 3.76 & 3.89 & 3.97 & 3.62 & 4.25 \\
\hline Appropriateness & 3.91 & 3.65 & 3.80 & 3.76 & 3.56 & 4.01 \\
\hline Attractiveness & 3.63 & 3.09 & 3.36 & 3.35 & 3.10 & 3.61 \\
\hline Empathy & 4.49 & 4.13 & 4.29 & 4.32 & 3.94 & 4.68 \\
\hline
\end{tabular}

Note: If a difference is significant, the background of the highest score is shaded.

Table 3. Self-assessments on test performance in relation to Gender, Ethnicity and School Type (correctness as percentage; easiness: minimum 1, maximum 7).

\begin{tabular}{|c|c|c|c|c|c|c|}
\hline & \multicolumn{2}{|c|}{ Gender } & \multicolumn{2}{|c|}{ Ethnicity } & \multicolumn{2}{|c|}{ School Type } \\
\hline & $\begin{array}{l}\text { Boy } \\
(n=471)\end{array}$ & $\begin{array}{l}\text { Girl } \\
(n=476)\end{array}$ & $\begin{array}{l}\text { Dutch } \\
(\mathrm{n}=472)\end{array}$ & $\begin{array}{l}\text { non-Dutch } \\
(\mathrm{n}=475)\end{array}$ & $\begin{array}{l}\text { Vocational } \\
(\mathrm{n}=477)\end{array}$ & $\begin{array}{l}\text { Grammar } \\
(n=470)\end{array}$ \\
\hline Correctness & 65.7 & 59.9 & 62.6 & 63.0 & 55.7 & 62.8 \\
\hline Easiness & 4.80 & 4.34 & 4.57 & 4.57 & 4.18 & 4.97 \\
\hline
\end{tabular}

Note: If a difference is significant, the background of the highest score is shaded.

Table 4. Text understanding in relation to Gender, Ethnicity and School Type (in percentage correct).

\begin{tabular}{|c|c|c|c|c|c|c|c|}
\hline & \multirow{2}{*}{ Overall } & \multicolumn{2}{|c|}{ Gender } & \multicolumn{2}{|c|}{ Ethnicity } & \multicolumn{2}{|c|}{ School Type } \\
\hline & & $\begin{array}{l}\text { Boy } \\
(n=471)\end{array}$ & $\begin{array}{l}\text { Girl } \\
(n=478)\end{array}$ & $\begin{array}{l}\text { Dutch } \\
(n=472)\end{array}$ & $\begin{array}{l}\text { non-Dutch } \\
(n=477)\end{array}$ & $\begin{array}{l}\text { Vocational } \\
(n=477)\end{array}$ & $\begin{array}{l}\text { Grammar } \\
(\mathrm{n}=472)\end{array}$ \\
\hline Level 1 & 88.5 & 87.1 & 89.8 & 87.9 & 89.0 & 84.0 & 92.9 \\
\hline Level 2 & 71.6 & 73.2 & 70.0 & 73.3 & 69.9 & 61.0 & 82.2 \\
\hline Level 3 & 75.6 & 76.1 & 75.1 & 77.1 & 74.0 & 65.5 & 85.6 \\
\hline Level 4 & 50.7 & 50.8 & 50.6 & 50.9 & 50.5 & 42.1 & 59.3 \\
\hline
\end{tabular}

Note: If a difference is significant, the background of the highest score is shaded.

\subsection{Text understanding}

Table 4 gives an overview of text understanding at each level in relation to gender, ethnicity, and school type. The overall pattern is in line with the idea that levels differ in complexity. The percentage of correct answers went down from 88.5 to 50.7, level 1 being most easy and level 4 least easy. Levels 2 and 3 take a position in between these two. The remaining results can be summarized as follows:

- Girls and boys hardly differed in their scores at all levels.

- Dutch and non-Dutch students showed no differences.

- Grammar schools students scored significantly higher than vocational school students on all four levels of understanding.

\section{Conclusion and discussion}

The PIRLS testing methodology has been successfully applied to an older age group than it was originally developed for. It proved feasible to construct a text-comprehension test on the basis of a single page passage from a literary novel, and to cast test items for each level of understanding in a multiple choice format. Scores conformed to the assumed difficulty of the test items. The dependent measures showed relations with personal characteristics similar to those found in our earlier studies. 
There were no effects for ethnicity, neither in self-assessments nor in actual performances [4]. Gender showed some differences but only with respect to subjective measures [5]. Girls were a bit more positive about their reading proficiency; boys were slightly more positive about their performance on the task. Boys also evaluated the text passage a bit more positively, but this did not give them any advantage on the test. The only real differences showed up with regard to school type. Grammar school students outperformed vocational school students on all four levels of understanding.

The methodology laid down in the PIRLS project has already offered practitioners highly valuable information on important aspects of literary reading, on attitudes and proficiencies of school children from very different countries and cultures. The division of text understanding into four levels differing in complexity is a very promising one; in fact, it has already proven to be a fruitful one. We hope to have shown here that this approach can be safely extended to older age groups as well. And also that it is possible to approach each level of understanding with the same objective and an easy-to-apply instrument, that is, with multiple choice items. There is one major task, however, that still needs to be undertaken. The practical success of the PIRLS methodology lacks a theoretical underpinning in current psycholinguistic models of the reading process. If such a theoretical underpinning was developed, this would add much to the validity of the approach. A certain amount of caution remains advisable here. However useful the information acquired this way might be, we need to continue to be critical of the outcomes and retain a healthy, perhaps not over-optimistic perspective on benchmarking in particular.

The study was conducted within the framework of the course Practical Interview and Survey, a required course in our first year Bachelor's program. We would like to thank all 115 students for their assistance in collecting and processing the survey data.

\section{References}

[1] M. Kistemaker, P. Broeder, and C. van Wijk (2013), Handling multilingualism in secondary education: a teachers' perspective. Proceedings of Inaugural European Conference on Language Learning “Shifting Paradigms: Informed Responses". Nagoya, Japan: IAFOR, p. 345-356

[2] I. Mullis, et al., PIRLS 2011 International Results in Reading (TIMSS \& PIRLS International Study Center, www.pirls.bc.edu)

[3] I. Mullis, et al., PIRLS 2011 Item Writing Guidelines (TIMSS \& PIRLS International Study Center, www.pirls.bc.edu

[4] P. Broeder, M. Stokmans, and C. van Wijk (2011), Verschillen in leesklimaat bij allochtonen en autochtonen in Nederland (www.cultuurnetwerk.nl) (Differences in reading climate of migrants and Dutch in the Netherlands)

[5] P. Broeder and M. Stokmans (2013), Why should I read? - A cross-cultural investigation into adolescents' reading socialisation and reading attitude, Int. Rev. Educ.

[6] A.F.Th. van der Heijden (1983), De slag om de Blauwbrug (The Battle of the Blue Bridge; Amsterdam: Querido) 